\title{
Escala diagramática para avaliação de severidade de mancha-de-septoria em girassol
}

\author{
Diagrammatic scale for assessment of septoria-leaf-spot severity in sunflower
}

\author{
Giuvan Lenz $^{\mathrm{I}^{*}}$ Ivan Dressler da Costa ${ }^{\mathrm{I}}$ Ricardo Silveiro Balardin ${ }^{\mathrm{I}}$ Maurício Silva Stefanelo \\ Leandro Nascimento Marques ${ }^{I}$ Adriano Arrué ${ }^{\mathrm{I}}$
}

\begin{abstract}
- NOTA -
RESUMO

A falta de um método-padrão de quantificação visual para doenças foliares pode levar a estimativas imprecisas da severidade dessas doenças, induzindo os avaliadores a conclusões erradas. O objetivo deste trabalho foi desenvolver uma escala diagramática para avaliação da mancha-deseptoria em girassol, causada por Septoria helianthi. Uma escala diagramática com cinco níveis $(2 ; 12 ; 26 ; 48,0$; e 71\%) foi desenvolvida e validada para quantificar a severidade da mancha-de-septoria em girassol. A escala considerou o limite de severidade máxima da doença observado no campo, e os níveis intermediários seguiram incrementos logarítmicos, obedecendo-se à "Lei do estímulo de Weber-Fechner". Inicialmente, a estimativa da severidade foi feita sem auxílio da escala em 30 folhas, com diferentes níveis de severidade,

and validated to assess septoria leaf spot in sunflower. The scale was developed considering the maximum limit of disease severity observed in the field and the intermediate values followed logarithmic increments according to the "Stimulus Law by Weber-Fechner". Initially the estimates of severity were performed without the use of the scale in 30 leaves with different levels of severity. Validation was carried out by eight appraisers, without previous practice in assessing septoria leaf spot in sunflower. Then, the appraisers estimated the severity of the same leaves previously assessed using the proposed diagrammatic scale. Assessments with the diagrammatic scale were of great precision for all raters and did not constitute systematic mistakes in overestimating or underestimating the disease severity. The proposed diagrammatic scale was considered adequate to estimate septoria-leaf-spot severity in sunflower.
\end{abstract} por oito indivíduos, sem experiência na avaliação de doenças. Em seguida, os mesmos avaliadores utilizaram a escala diagramática proposta. As avaliações com a escala diagramática foram mais precisas e acuradas nas estimativas de todos os avaliadores, não ocorrendo erro sistemático na superestimativa ou subestimativa da doença entre estes. A escala diagramática proposta foi considerada adequada para estimar a severidade de mancha-de-septoria em girassol.

Palavras-chave: fitopatometria, mancha foliar, Septoria helianthi

\section{ABSTRACT}

The lack of a standardized visual method may lead to inaccurate estimative of severity and wrong conclusions. The objective of this research was to develop a diagrammatic scale to assess the severity of septoria leaf spot in sunflower, caused by Septoria helianthi. A diagrammatic scale with five levels of disease severity $(2 ; 12 ; 26 ; 48$; and $71 \%)$ was developed
Key words: leaf spot, phytopatometry, Septoria helianthi

O fungo Septoria helianthi foi originalmente relatado nos Estados Unidos da América, em 1924 (HENRY \& GILBERT, 1925), e posteriormente na Índia e no Paquistão (HAMID \& JALALUDDIN, 2007). No Estado do Rio Grande do Sul, foi recentemente descoberto, causando manchas foliares e danos consideráveis em girassol (Helianthus annus L.). Como sintomas, observam-se manchas de coloração marrom-escura, de formato irregular, com pequeno halo amarelado e com diâmetro variando entre 10 e 18mm, que, com o avanço da doença, coalescem, principalmente a partir das margens das folhas.

'Departamento de Defesa Fitossanitária, Centro de Ciências Rurais (CCR), Universidade Federal de Santa Maria (UFSM), 97105900, Santa Maria, RS, Brasil. E-mail: giuvanlenz@gmail.com. *Autor para correspondência. 
Como é estimada visualmente, a quantificação da severidade das doenças está sujeita a grande subjetividade e pode induzir graves erros. A quantificação de uma variável que expresse a intensidade de doença, por incidência ou severidade, é fundamental, para descrever o progresso da epidemia e sua relação com o clima ou com medidas de controle, bem como para validação de modelos de previsão ou aplicação do manejo integrado, como já demonstrado por vários autores em outros patossistemas (MARTINS et al., 2004; MAZARO et al., 2006; BARGUIL et al., 2008).

Nesse contexto, este trabalho teve como objetivos desenvolver uma escala diagramática para avaliação da severidade da mancha-de-septoria e analisar os níveis de acurácia, precisão e reprodutibilidade das estimativas geradas com sua utilização em trabalhos epidemiológicos.

Para elaboração da escala diagramática, foram coletadas 100 folhas de girassol de diversas cultivares no Município de Santa Maria, Rio Grande do Sul (RS), com diferentes níveis de severidade de Septoria helianthi. As folhas foram digitalizadas com resolução de 300dpi. Com o auxílio do programa Sigma Scan Pro v. 5.0, Jandel Scientific, foram determinadas a área foliar total e a área necrótica de cada folha, obtendose a severidade da doença (percentagem de área foliar lesionada). Utilizando o valor máximo de severidade da doença constatada nas folhas coletadas, os intervalos da escala foram calculados com o auxílio do programa 2LOG (TOVAR-SOTO et al., 2002). Com base na lei de Weber-Fechner de acuidade visual (HORSFALL \& COWLING, 1978), bem como na forma, distribuição e frequência das lesões, foi confeccionada uma escala diagramática logarítmica com cinco níveis de severidade (Figura 1). Nessa escala foram representados os sintomas de cada nível, procurando-se manter os padrões de distribuição das lesões.

Para validação da escala diagramática proposta, foram tomadas 30 folhas, com diferentes níveis de severidade, e apresentadas para oito avaliadores sem experiência prévia na avaliação de doenças, que estimaram a severidade da mancha-deseptoria em uma primeira etapa sem e, posteriormente, com a escala diagramática. A acurácia e a precisão das estimativas visuais de cada avaliador foram determinadas por regressão linear simples, considerando a severidade real como variável independente e a severidade estimada como variável dependente (Figura 2). A precisão das estimativas foi avaliada pelo coeficiente de determinação da regressão $\left(\mathrm{r}^{2}\right)$ e pela variância dos erros absolutos (severidade estimada menos severidade real). O programa Microsoft Excel 2007 foi utilizado nas análises de regressão linear.

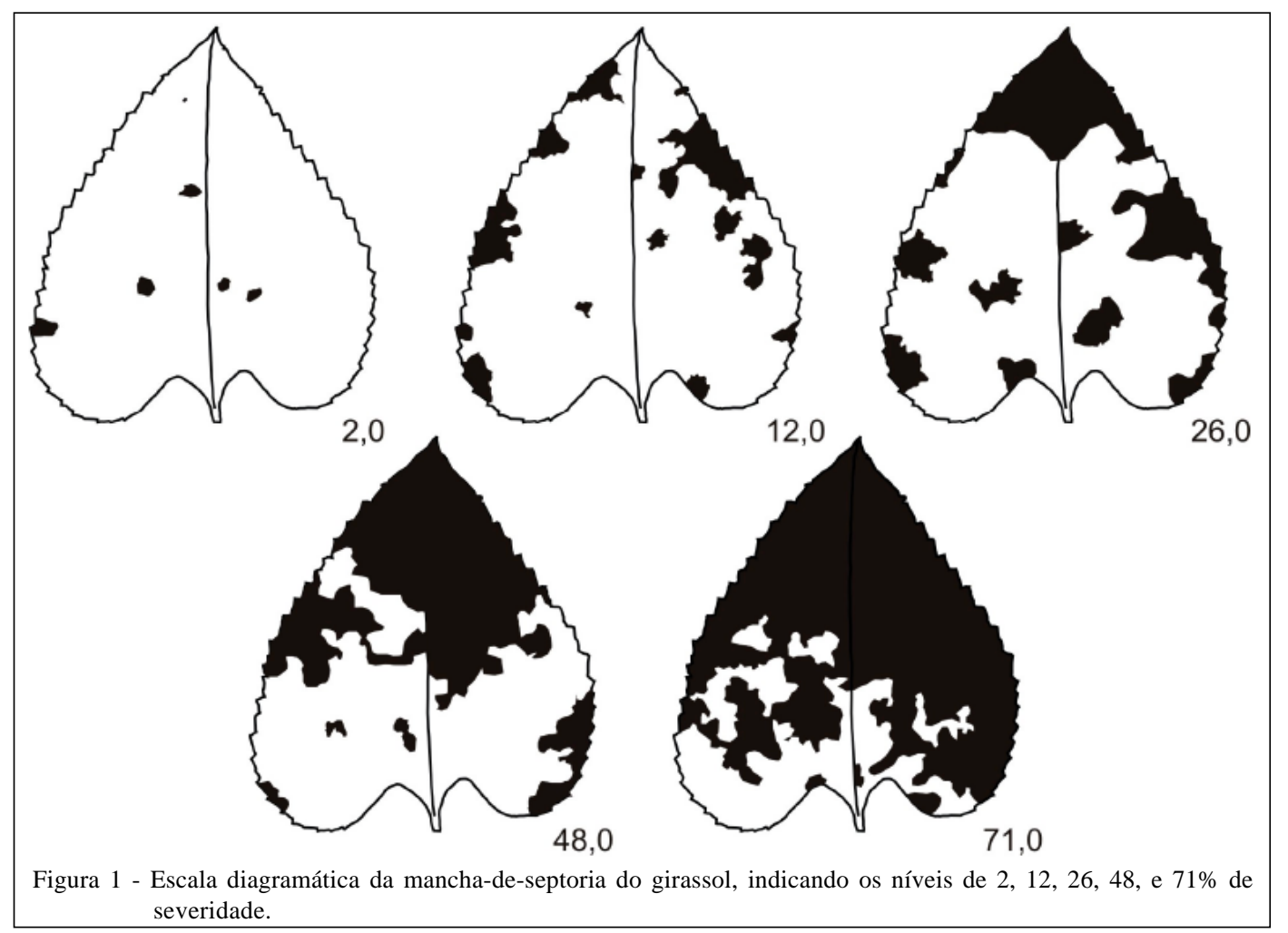

Ciência Rural, v.39, n.8, nov, 2009. 


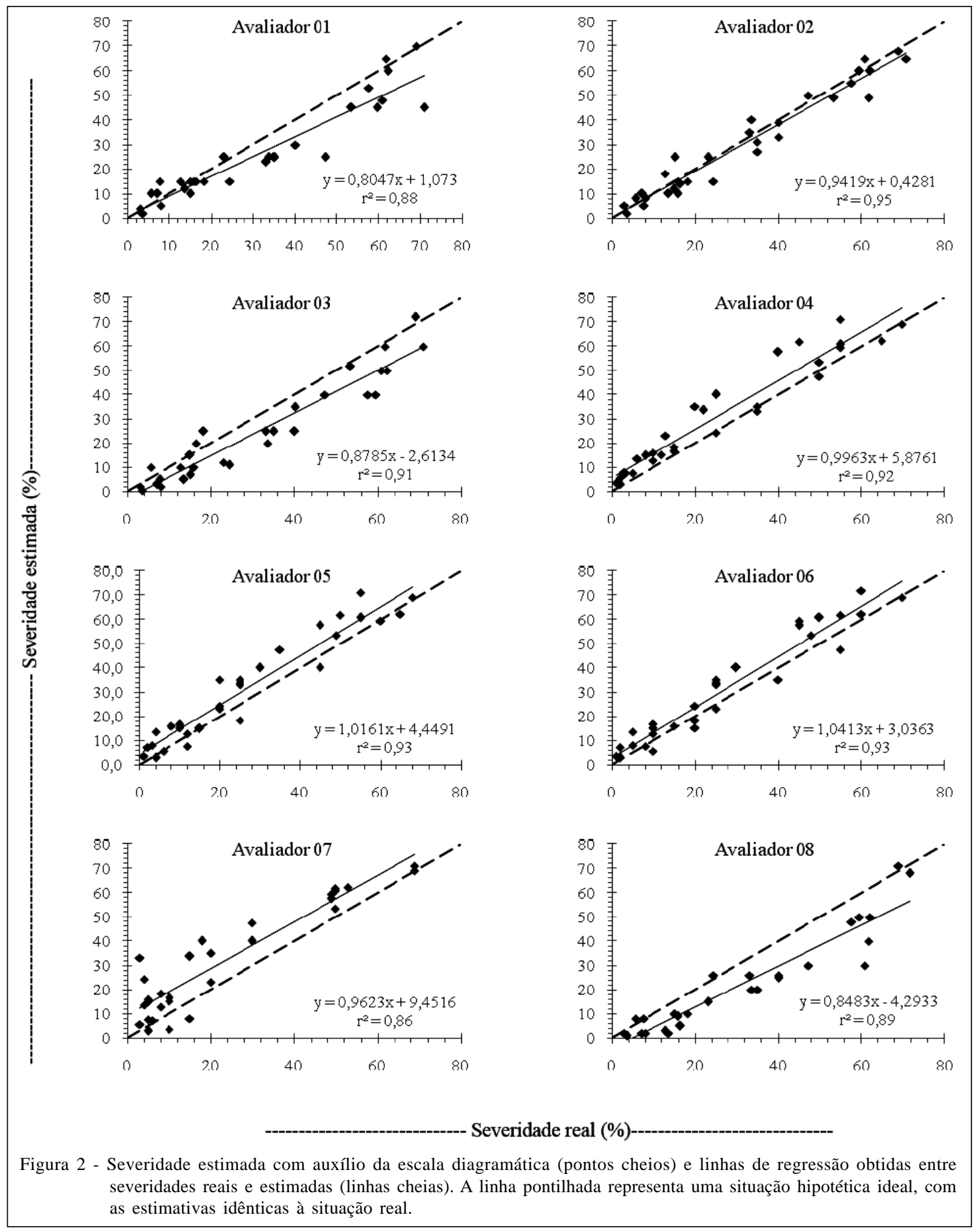

Na validação da escala diagramática, todos os avaliadores mostraram-se com acurácia, pois os valores estimados de severidade ficaram próximos dos valores da severidade real. Conforme BERGAMIN FILHO \& AMORIM (1996), valores próximos entre valores estimados e os valores reais determinam a acurácia das avaliações.
Com a utilização da escala diagramática proposta para mancha-de-septoria em girassol, os avaliadores apresentaram boa precisão, com coeficiente de determinação entre 0,86 e 0,93 . Sem o uso da escala, esse valor ficou de 0,59 a 0,84 , indicando que, com o uso da escala, as estimativas foram sistematicamente relacionadas com o valor real. Essa melhoria tem sido 
verificada com a utilização de outras escalas diagramáticas (SPOSITO et al., 2004; NASCIMENTO et al., 2005), o que demonstra a importância dessa ferramenta em estudos de quantificação de doenças.

A precisão, conforme BERGAMIN FILHO \& AMORIM (1996), é um fator a ser considerado na validação de uma escala diagramática e é definida como a exatidão de uma operação em que há rigor ou refinamento na medida. A precisão pode ser avaliada por meio do coeficiente de determinação da regressão, que deve ser próximo de $100 \%$, e pela variação dos erros absolutos expressa pela diferença entre severidade estimada e real.

Além do coeficiente de correlação, a precisão dos avaliadores foi observada com a determinação do erro absoluto ou resíduo, ou seja, a diferença entre a severidade estimada e a real. Os valores obtidos de resíduos permaneceram dentro dos valores aceitáveis $(-10 \mathrm{a}+10)$, segundo critérios adotados por programas de computadores para treinamento na quantificação de doenças como Distrain e Disease Pro (MARTINS et al., 2004).

Os níveis de acurácia, precisão e reprodutibilidade das mensurações da severidade da mancha-de-septoria em girassol melhoraram significativamente com o uso da escala diagramática, indicando que sua adoção em estudos epidemiológicos poderá reduzir a subjetividade das estimativas e propiciar informações mais precisas a respeito do patossistema Septoria helianthi em girassol, além de proporcionar uma padronização das avaliações de severidade, permitindo assim a comparação de resultados entre diferentes instituições e locais.

\section{REFERÊNCIAS}

BARGUIL, B.M. et al. Escala diagramática para avaliação da severidade da antracnose em bastão do imperador. Ciência Rural, v.38, n.3, p.807-810, 2008. Disponível em: <http:// www.scielo.br/scielo.php?script=sci_arttext\&pid=S0103- 84782008000300034\&lang=pt>. Acesso em: 01 jul. 2009. doi: 10.1590/S0103-84782008000300034.

BERGAMIN FILHO, A.; AMORIM, L. Doenças de plantas tropicais: epidemiologia e controle econômico. São Paulo: Agronômica Ceres, 1996. 299p.

HAMID, M.; JALALUDDIN, M. A new report of Septoria helianthi leaf spot of sunflower from Sindh. Pakistan Journal of Botany, v.39, n.1, p.659-660, 2007.

HENRY, A.W.; GILBERT, H.C. Important diseases of the common sunflower. Minnesota Studies in Plant Science, v.5, n.2, p.285, 1925.

HORSFALL, J.G.; COWLING, E.B. Pathometry: the measurement of plant disease. In: ___ _ _ (Ed.). Plant disease: an advanced treatise - how disease develops in populations. New York: Academic, 1978. V.2, p.119-136.

MARTINS, M.C. et al. Escala diagramática para a quantificação do complexo de doenças foliares de final de ciclo em soja. Fitopatologia Brasileira, v.29, n.2, p.179-184, 2004. Disponível em: <http://www.scielo.br/scielo.php?pid=S010041582004000200009\&script $=$ sci_arttext \&tlng=es $>$. Acesso em: 01 jul. 2009. doi: 10.1590/S0100-41582004000200009.

MAZARO, S.M. et al. Escala diagramática para avaliação da severidade da mancha-de-micosferela em morangueiro. Ciência Rural, v.36, n.2, p.648-652, 2006. Disponível em: < http:// www.scielo.br/scielo.php?script=sci_arttext\&pid=S0103$84782006000200045>$. Acesso em: 01 jul. 2009. doi: 10.1590/ S0103-84782006000200045.

NASCIMENTO, A.R.P. et al. Elaboração e validação de escala diagramática para cancro bacteriano da videira. Summa Phytopathologica, v.31, n.1, p.59-64, 2005.

SPOSITO, M.B. et al. Elaboração e validação de escala diagramática para avaliação da severidade da mancha preta em frutos cítricos. Fitopatologia Brasileira, v.29, n.1, p.81-85, 2004. Disponível em: <http:/www.scielo.br/scielo.php?script=sci_arttext\&pid=S010041582004000100012>. Acesso em: 01 jul. 2009. doi: 10.1590/ S0100-41582004000100012.

TOVAR-SOTO, A. et al. Escala logarítimica diagramática de severidad de la mancha negra (Colletotrichum gloeosporioides Penz.) en Chirimoyo (Annona cherimola Mill). Revista Mexicana de Fitopatología, v.20, n.1, p.103-109, 2002. 